\title{
Polypharmacy: A Case Report and New Protocol for Management
}

\section{R. David Lee, $M D$}

Background: Polypharmacy is an important issue in primary care, yet few data are available concerning its prevalence, complications, and management in clinical medicine. The following case illustrates the clinical perils of polypharmacy and serves as a point for critical discussion.

Metbods: MEDLINE was searched, using the key word "polypharmacy," from 1994 to the present. A case report of polypharmacy is described, and a novel protocol for the management of polypharmacy is proposed.

Results: Polypharmacy can lead to unnecessary expense, wasted time, and embarrassment on the part of the patient and confusion and mismanagement on the part of the physician. The literature reveals controversy surrounding the definition of polypharmacy and reflects the considerable morbidity and expense associated with polypharmacy. Finally, the SAIL protocol shows that physicians need to keep in mind simplicity, adverse effects, indications, and a precise list of all medications to manage appropriately a patient's drug regimen.

Conclusions: Polypharmacy is associated with morbidity and iatrogenic complications. The SAIL protocol can be a useful tool in the management of this entity. More research needs to be done on the prevalence, complications, and management of polypharmacy. (J Am Board Fam Pract 1998;11:140-4.)

Polypharmacy is a major problem in clinical practice, ${ }^{1-6}$ yet clinically relevant data regarding its prevalence, complications, and treatment are scarce. ${ }^{7-11}$ Even the definition of polypharmacy is controversial ${ }^{12}$ and varies from study to study, which further complicates the translation of research results into useful information for the practicing primary care physician.

\section{Methods}

Using the key word "polypharmacy," the medical literature was searched through MEDLINE for reports of polypharmacy and to review definitions, possible complications, and interventions. A case report describes a patient in whom polypharmacy led to misdiagnosis, unnecessary testing, and inappropriate treatment. Finally, a protocol for appropriate prescribing based on the SAIL acronym is proposed.

\section{Case Report}

A 67-year-old woman attended a family practice office for treatment of refractory hypertension.

Submitted, revised 3 July 1997.

From the Blackstone Family Practice Center, Department of Family Practice, Medical College of Virginia, Richmond. Address reprint requests to $\mathrm{R}$. David Lee, $M D$, Page Rural Health Center, 294 East Main St, Stanley, VA 22851.
She had a medical history of high blood pressure, enlarged heart, and gout. Records from her previous physician did not further clarify her history. Her medications included digoxin $0.25 \mathrm{mg}$ daily, furosemide $40 \mathrm{mg}$ daily, potassium chloride 10 $\mathrm{mEq}$ twice daily, isosorbide dinitrate $40 \mathrm{mg}$ daily, isradipine $2.5 \mathrm{mg}$ daily, and allopurinol $300 \mathrm{mg}$ as needed for gout.

She had no physical complaints and no unusual findings when questioned. Her last exacerbation of gout had been several years earlier. She was a retired nurses' aide, had never smoked, and did not drink alcohol. Her family history was notable only for hypertension in her mother.

During a complete physical examination, her blood pressure was $154 / 94 \mathrm{mmHg}$, pulse 80 beats per minute, respiratory rate $22 / \mathrm{min}$, and temperature of $36.2^{\circ} \mathrm{C}$. Head and neck examination revealed $\mathrm{A}-\mathrm{V}$ nicking on funduscopy. Findings of the remainder of the physical examination were normal. Trichomonas infection was found incidentally on Papanicolaou smear and treated with a single 2$\mathrm{g}$ dose of metronidazole.

Chemistry values included sodium $144 \mathrm{mEq} / \mathrm{L}$, potassium $3.7 \mathrm{mEq} / \mathrm{L}$, blood urea nitrogen 15 $\mathrm{mg} / \mathrm{dL}$, creatinine $1.0 \mathrm{mg} / \mathrm{dL}$, glucose $420 \mathrm{mg} / \mathrm{dL}$, and uric acid $7.9 \mathrm{mg} / \mathrm{dL}$. Her cholesterol level was $188 \mathrm{mg} / \mathrm{dL}$ with a low-density lipoprotein level of 
$118 \mathrm{mg} / \mathrm{dL}$ and a high-density lipoprotein level of $35 \mathrm{mg} / \mathrm{dL}$. Complete blood count, thyroid function, and hepatic function were normal. Digoxin level was $0.8 \mu \mathrm{g} / \mathrm{L}$. Electrocardiographic findings were normal.

Diabetes mellitus was diagnosed and treated with metformin $500 \mathrm{mg}$ twice daily and glyburide $5 \mathrm{mg}$ twice daily with normoglycemic results.

Further work-up for secondary causes of hypertension, including a renal scan using captopril, urine screening for pheochromocytoma, and an echocardiogram, was negative. A cardiologist and a nephrologist were consulted, but their recommendations did not result in improved control of her hypertension. Several more antihypertensive medications were added to her previous medication regimen and titrated to the following doses: isradipine $5 \mathrm{mg}$ twice daily, captopril $25 \mathrm{mg}$ three times daily, lisinopril $10 \mathrm{mg}$ twice daily, clonidine $0.4 \mathrm{mg}$ in the mornings and $0.2 \mathrm{mg}$ in the evenings, metoprolol $50 \mathrm{mg}$ twice daily, doxazosin 4 $\mathrm{mg}$ daily, and sustained-release verapamil $240 \mathrm{mg}$ daily. The clonidine was eventually withdrawn gradually and discontinued because of untoward side effects.

The patient's blood pressure varied markedly between office visits, ranging from $130 / 80 \mathrm{mmHg}$ to $194 / 118 \mathrm{mmHg}$. This lability was noted by various examiners and did not depend on whether the patient was examined in the office or at her home by a home health nurse or a neighbor. Also of interest was that although her blood glucose levels obtained in the office were between 80 and 100 $\mathrm{mg} / \mathrm{dL}$, her glycohemoglobin level was consistently between 8.0 and 9.0 percent.

When questioned about medication compliance on several occasions, the patient always appeared to be sincere in her efforts to manage her health and, in fact, missed only 2 of 38 appointments during this time. She was insured through Medicare and Medicaid, and it was assumed that her prescriptions were covered services.

After nearly 3 years of evaluation and treatment for refractory hypertension, she confided to a physician that her prescriptions cost more than $\$ 400$ a month, and her sole source of monthly income was a Social Security check for \$600! Prescription costs were not covered by her insurance carriers. She admitted tearfully that she was embarrassed about not being able to pay for her medications and would rotate them so that she would take one pill for several days in a row, then switch to another. In this way, she would be able to take all of her prescriptions while making each last longer. For example, on the days leading up to a scheduled blood glucose check, she would faithfully take her hypoglycemic agents but afterward would start taking another medication. Switching medications accounted for her normal blood glucose but elevated glycohemoglobin levels during office visits and her fluctuating blood pressure readings.

All medications except glyburide $5 \mathrm{mg}$ once daily were discontinued, and her antihypertensive medications were then resumed after obtaining a baseline blood pressure of $150 / 98 \mathrm{mmHg}$. The patient's blood pressure was finally stabilized on a daily combination of $5 \mathrm{mg}$ of amlodipine $/ 10 \mathrm{mg}$ of benzapril and $4 \mathrm{mg}$ of doxazosin. Upjohn is currently supplying this patient with glyburide (Micronase $\left.{ }^{\circledR}\right)$, Ciba is supplying her with amlodipine/ benazepril (Lotrel $5 / 10^{\circledR}$ ), and Pfizer is supplying her with doxazosin (Cardura ${ }^{\circledR}$ ) through their respective indigent programs. The patient's diabetes and hypertension both appear to be well-controlled. Her most recent blood pressure was $122 / 80 \mathrm{mmHg}$, and her glycohemoglobin was 7.2 percent.

\section{Discussion}

Although the above case is extreme, it illustrates several issues that the primary care physician must consider when prescribing multiple medications for a patient (Table 1). Polypharmacy is an iatrogenic condition, and because of a delayed diagnosis, this patient had to deal not only with the expense of superfluous medications but also the time lost to her appointments, tests, and referrals, in addition to undue embarrassment and guilt about her financial situation. Additionally, her complex regimen led to two physician-prescribing errors, which were later discovered and documented in the chart. There were also multiple errors made when transcribing her medication list from visit to visit, which were not noticed by the prescribing physicians. In summary, this case illustrates how polypharmacy placed an unwarranted social burden on a patient who was trying to be responsible for her health and how it also led to mismanagement of her care by physicians.

Polypharmacy in its strictest sense is the concomitant use of many drugs. ${ }^{13}$ In clinical practice, 
Table 1. Clinical Profile of Patient Before and After Diagnosis of Polypharmacy.

\begin{tabular}{|c|c|c|}
\hline Clinical Markers & Clinical Profile Before Diagnosis & Clinical Profile After Diagnosis \\
\hline Medications & $\begin{array}{l}\text { Allopurinol } 300 \mathrm{mg} \text { as needed } \\
\text { Captopril } 25 \mathrm{mg} \text { tid } \\
\text { Clonidine } 0.4 \mathrm{mg} \text { each morning, } \\
0.2 \mathrm{mg} \text { every evening } \\
\text { Digoxin } 0.25 \mathrm{mg} \text { qd } \\
\text { Doxazosin } 4 \mathrm{mg} \text { qd } \\
\text { Furosemide } 40 \mathrm{mg} \text { qd } \\
\text { Glyburide } 5 \mathrm{mg} \text { bid } \\
\text { Isosorbide dinitrate } 40 \mathrm{mg} \mathrm{qd} \\
\text { Isradipine } 5 \mathrm{mg} \text { bid } \\
\text { Lisinopril } 10 \mathrm{mg} \text { bid } \\
\text { Metformin } 500 \mathrm{mg} \mathrm{bid} \\
\text { Metoprolol } 50 \mathrm{mg} \text { bid } \\
\text { Potassium chloride } 10 \mathrm{mEq} \text { bid } \\
\text { Verapamil } 240 \mathrm{mg} \text { qd }\end{array}$ & $\begin{array}{l}\text { Amlodipine } 5 \mathrm{mg} / \text { benazepril } 10 \mathrm{mg} \text { qd } \\
\text { Doxazosin } 4 \mathrm{mg} \text { qd } \\
\text { Glyburide } 5 \mathrm{mg} \text { qd }\end{array}$ \\
\hline Mean blood pressure & $\begin{array}{l}\text { Systolic, } 149 \mathrm{mmH} \\
\text { Diastolic, } 95 \mathrm{mmHg}\end{array}$ & $\begin{array}{l}\text { Systolic, } 130 \mathrm{mmH} \\
\text { Diastolic, } 82 \mathrm{mmH}\end{array}$ \\
\hline Referrals & $\begin{array}{l}\text { Cardiologist } \\
\text { Nephrologist }\end{array}$ & Annual ophthalmologic screening \\
\hline Laboratory studies & $\begin{array}{l}\text { Comprehensive chemistry panel } \\
\text { Complete blood count } \\
\text { Thyroid function panel } \\
\text { Digoxin level } \\
\text { Glycohemoglobin } \\
\text { Urine pheochromocytoma screening }\end{array}$ & Routine health maintenance only \\
\hline Other studies & $\begin{array}{l}\text { Electrocardiogram } \\
\text { Echocardiogram } \\
\text { Captopril renal scan }\end{array}$ & \\
\hline $\begin{array}{l}\text { Average frequency of } \\
\text { appointments }\end{array}$ & $\begin{array}{l}\text { Every } 21.6 \mathrm{~d} \text { for } 3 \text { y plus multiple } \\
\text { physician-initiated home nursing visits }\end{array}$ & Scheduled for every 3-6 mo \\
\hline
\end{tabular}

*Discontinued because of side effects.

however, polypharmacy implies the prescribing of excessive medication. ${ }^{13}$ There are two definitions for polypharmacy in the literature in terms of what is excessive in one's drug regimen.

One definition focuses only on the number of drugs the patient is taking. The authors disagree, however, on the number of drugs and whether to include as-needed medications, over-the-counter drugs, or herbal and alternative medications. ${ }^{12}$ Polypharmacy has been variously defined as the concomitant use of more than 2 drugs, ${ }^{14} 4$ drugs, ${ }^{15}$ 5 drugs, ${ }^{15,16} 6$ drugs $^{17}$ and 10 drugs. ${ }^{12}$

The other way to define polypharmacy is to focus only on the clinical indications and effects of a given drug regimen, regardless of the number of drugs used. Polypharmacy would therefore mean that more medications are used or prescribed than are clinically indicated. ${ }^{18}$ This broader definition, while making outcomes research on polypharmacy logistically more difficult, allows for an individualized approach to a patient's drug regimen. ${ }^{19}$ For example, a patient who has suffered a myocardial infarction might be discharged from the hospital with prescriptions for aspirin, a nitrate, a $\beta$ blocker, an angiotensin-converting enzyme (ACE) inhibitor, and a lipid-lowering agent. Although the patient is taking five medications, this regimen would not be considered polypharmacy because each drug is clinically necessary, and the regimen is associated with improved survival. ${ }^{20}$ Cancer, ${ }^{21}$ congestive heart failure, ${ }^{22}$ diabetes mellitus, ${ }^{23}$ and the acquired immune deficiency syndrome ${ }^{24}$ are 
Table 2. Reported Complications of Polypharmacy.

Increased total medical expenses ${ }^{12}$

Increased incidence of adverse drug effects ${ }^{12,16}$

Decreased patient compliance ${ }^{12}$

Decreased social activity ${ }^{17}$

Increased incidence of depression ${ }^{17}$

Diminished cognition ${ }^{17}$

Increased incidence of eventual nursing home placement ${ }^{15}$

Increased prescribing errors ${ }^{18}$

diseases for which prescribing multiple drugs concomitantly is associated with decreased morbidity and mortality. On the other hand, a patient who takes only digoxin would be considered to have polypharmacy if there were no indication for this prescription.

Polypharmacy led to serious complications in the patient described and has been associated with an increase in morbidity as well (Table 2). Hamdy et al ${ }^{12}$ concluded that polypharmacy was associated with an increase in a patient's total medical expense, a decrease in patient compliance, and an increase in the incidence of adverse drug effects. Burns et al ${ }^{17}$ found decreased social activity, increased incidence of depression, and decreased cognition in patients with polypharmacy. Satish et al ${ }^{15}$ concluded that polypharmacy in the elderly is an independent risk factor for eventual nursing home placement. Carlson ${ }^{18}$ reported an increased incidence of prescribing errors on the part of the clinicians whose patients had polypharmacy.

\section{SAIL: A New Protocol for the Management of Polypharmacy}

Polypharmacy is associated with adverse complications and is frequently iatrogenic. The precise number of drugs the patient is taking appears to be less important than the clinician's ability to relate the use of each drug to the patient's medical, social, and economic circumstances. ${ }^{18}$ It is imperative that physicians recognize and manage polypharmacy aggressively.

It is with the above in mind that I have developed the SAIL protocol for appropriate prescribing (Table 3). This mnemonic is intended to help physicians minimize polypharmacy in their clinical practice. Simple drug regimens can usually be achieved by prescribing drugs that can be taken once daily ${ }^{18}$ and by changing to a single combination pill when adding a second drug. ${ }^{6}$ Although the direct cost of such a regimen might be higher in the short-term, the potential costs of long-term polypharmacy must be weighed when considering the economics of a particular regimen. ${ }^{25}$. The physician must also possess a thorough knowledge of the adverse effects of all drugs the patient is taking, ${ }^{6,8,26}$ including the side effects of a drug as well as its interactions with other drugs. The indication for each drug the patient is taking must be clearly understood. ${ }^{18,26}$ Each drug should have a well-defined therapeutic goal and must achieve the desired goal or be eliminated from the patient's medication list. ${ }^{18}$ Finally, the physician and the patient both should have an accurate and current list of the medications. ${ }^{18,26-28}$ This list must include all prescriptions, over-the-counter medications, asneeded medications, and herbs and other alternative medicines.

Although the SAIL protocol has not yet been tested in clinical practice, its application in this particular case shows how it can be effective in managing polypharmacy. The patient's regimen was simplified by structuring her drug regimen to include only medicines that are taken once daily. Additionally, prescribing a combination drug amlodipine/benzapril rather than a calcium channel blocker plus an ACE inhibitor decreases the total number of pills the patient has to take. Drugs with adverse effects, such as clonidine, and drugs with potential adverse effects, such as digoxin and allopurinol, were discontinued. Several drugs that had no indication, such as digoxin, allopurinol, and isosorbide dinitrate, were discontinued. Fi-

\section{Table 3. The SAIL Protocol for Appropriate Prescribing}

Simple
The drug regimen must be as simple as possible
Prescribe combination drugs, when possible
Aim for once-daily regimens
Possible adverse effects of each drug must be
clearly understood
Drugs must have a wide therapeutic window
Drugs must not interact with other drugs in the
regimen
The indication for each drug must be clear
Each drug must have a clearly defined
therapeutic goal
Each drug must achieve the desired therapeutic
goal
The list of drugs in the regimen must be
accurate
The list of drugs must include prescriptions,
over-the-counter medications, and herbs or
alternative medications
The patient's list must correspond to the
physician's list


nally, prescribing errors occurred because clinicians had not maintained an accurate, up-to-date list of this patient's medications, as evidenced by the patient taking two ACE inhibitors simultaneously. Reducing the list of medicines to three pills a day has made her drug regimen more manageable both for the patient and her physicians. In this patient, the SAIL protocol managed polypharmacy effectively and reduced its complications, morbidity, and cost.

\section{Conclusion}

Polypharmacy can be defined as the administration and use of pharmacological agents for which there is no indication. Such medication misuse is prevalent in clinical practice and is associated with high morbidity and high economic costs. The SAIL protocol can help physicians reduce polypharmacy in their own practice. More research is needed in the areas of prevalence, complications, and treatment of this problem.

\section{References}

1. Avorn J, Gurwitz JH. Drug use in the nursing home. Ann Intern Med 1995;123:195-204.

2. Lai MS, Chu CS, Lin SH, Lin MS. Prescribing patterns in primary health care in Taiwan. Int J Clin Pharmacol Ther 1995;33:437-41.

3. Smith DM, Cox MR, Brizendine EJ, Hui SL, Freedman JA, Martin DK, et al. An intervention on discharge polypharmacy. J Am Geriatr Soc 1996;44: 416-19.

4. Smith NK, Albazzaz MK. A prospective study of urinary retention and risk of death after proximal femoral fracture. Age Ageing 1996;25:150-4.

5. Von Korff M, Galer BS, Stang P. Chronic use of symptomatic headache medications. Pain 1995;62: 179-86.

6. Drake AC, Romano E. How to protect your older patients from the hazards of polypharmacy. Nursing 1995;25:34-9.

7. Miller DK, Carter ME, Sigmund RH, Smith JQ, Miller JP, Bentley JA, et al. Nutritional risk in innercity-dwelling older black Americans. J Am Geriatr Soc 1996;44:959-62.

8. Kiivet RA, Llerena A, Dahl ML, Rootslane L, Sanchez Vega J, Eklundh T, et al. Patterns of drug treatment of schizophrenic patients in Estonia, Spain, and Sweden. Br J Clin Pharmacol 1995;40: $467-76$.

9. Lammers MW, Hekster YA, Keyser A, van Lier H, Meinardi H, Renier WO. Neither dosage nor serum levels of antiepileptic drugs are predictive for efficacy and adverse effects. Pharm World Sci 1995;17:201-6.

10. Bingefors KA, Isacson DG, von Knorring L,
Smedby B. Prescription drug and healthcare use among Swedish patients treated with antidepressants. Ann Pharmacother 1995;29:566-72.

11. Lacro JP, Jeste DV. Physical comorbidity and polypharmacy in older psychiatric patients. Biol Psychiatry 1994;36:146-52.

12. Hamdy RC, Moore SW, Whalen K, Donnelly JP, Compton R, Testerman F, et al. Reducing polypharmacy in extended care. South Med J 1995;88:534-8.

13. Dorland's illustrated medical dictionary. 26th ed. Philadelphia: WB Saunders, 1985.

14. Ferrendelli JA. Relating pharmacology to clinical practice: the pharmacologic basis of rational polypharmacy. Neurology 1995;45(3 Suppl 2):S12-6.

15. Satish S, Winograd CH, Chavez C, Bloch DA. Geriatric targeting criteria as predictors of survival and health care utilization. J Am Geriatr Soc 1996; 44:914-21.

16. Hanlon JT, Weinberger M, Samsa GP, Schmader $\mathrm{KE}$, Uttech KM, Lewis IK, et al. A randomized, controlled trial of a clinical pharmacist intervention to improve inappropriate prescribing in elderly outpatients with polypharmacy. Am J Med 1996;100: 428-37.

17. Burns R, Nichols LO, Graney MJ, Cloar FT. Impact of continued geriatric outpatient management on health outcomes of older veterans. Arch Intern Med 1995;155:1313-8.

18. Carlson JE. Perils of polypharmacy: 10 steps to prudent prescribing. Geriatrics 1996;51:26-30, 35.

19. Sachs GS. Bipolar mood disorder: practical strategies for acute and maintenance phase treatment. J Clin Psychopharmacol 1996;16(2 Suppl 1):32S-47S.

20. Jollis JG, DeLong ER, Peterson ED, Muhlbaier LH, Fortin DF, Califf RM, et al. Outcome of acute myocardial infarction according to the specialty of the admitting physician. N Engl J Med 1996;335: 1880-7.

21. Kerr IG. Clinical trials to study pain in patients with advanced cancer: practical difficulties. Anticancer Drugs 1995;6(Suppl 3):18-28.

22. Remme WJ. Neurohormonal modulation in heart failure: ACE inhibition and beyond. Eur Heart J 1995;16(Suppl N):73-8.

23. Tattersall $R$. Traditional pharmacologic management of non-insulin dependent diabetes. Clin Invest Med 1995;18:288-95.

24. Henry K. Management of HIV infection. A 1995-96 overview for the clinician. Minn Med 1995;78:1724.

25. Mooradian AD. Drug therapy of non-insulin-dependent diabetes mellitus in the elderly. Drugs 1996; 51:931-41.

26. Sadowski AV, Redeker NS. The hypertensive elder: a review for the primary care provider. Nurse Pract 1996;21:99-102, 105-112, 118.

27. Ferrendelli JA. Rational polypharmacy. Epilepsia 1995;36(Suppl 2):S115-8.

28. Stewart RB, Cooper JW. Polypharmacy in the aged. Practical solutions. Drugs Aging 1994;4:449-61. 